\title{
Ansprache gehalten am 18. III. 1923
}

\begin{tabular}{|l|l|l|}
\hline W. & Wilhelm & Mühsam \\
\hline
\end{tabular}

Hochverehrter Meister!

Ein gütiges Geschick hat die Wünsche und Hoffnungen, die Ihnen zum 70. Geburtstage ausgesprochen worden sind, erfü,llt und setzt uns in die angenehme Lage, Ihnen heute zum 80. unsere herzlichen Glückwünsche und unsere aufrichtige Ver-ehrung aufs neue ausdrü,cken zu können.

Diese zehn Jahre, die unserem Vaterlande das schwerste gebracht haben, was je einem Volke auferlegt gewesen ist, und die manchen Jüngeren in tatenlose Mutlosigkeit getrieben haben, haben Ihnen kaum etwas anhaben können: In körperlicher Rü,stig-keit, in geistiger Frische und in seelischer Ausgeglichenheit stehen Sie, der Sie doch mit jeder Faser Ihres Herzens das Leiden des Vaterlandes mitempfinden, uns heute gegenüber. Das verdanken Sie der Erkenntnis, daß seelische Niedergeschlagenheit kaum besser überwunden werden kann als durch Arbeit, und so hat Ihre Schaffensfreude und das Pflichtgefühl Ihrem Werke gegenüber auch im vergangenen Jahrzehnt wieder Leistungen gezeitigt, die nirgends einen Zug von Greisenhaftigkeit erkennen lassen, und die beweisen, daß die geistigen Werte einer Nation selbst dem Vernichtungswillen eines unerbittlichen Siegers standhalten.

Als einzig überlebender Assistent des genialen Reformators der Augenheilkunde, dessen liebevoll gezeichnetes Lebensbild wir Hirer, \ron dankbarer Anhänglichkeit geführten Feder verdanken, ragen Sie in unsere Zeit hinein. Sie haben die Loslösung der Augenheilkunde von der Chirurgie miterlebt und haben durch Ihr Wirken die Berechtigung der Selbständigkfeit unseres Sonder-faches erwiesen.

In jahrzehntelanger klinischer Tätigkeit haben Sie sich den Dank ungezählter Kranker erworben, denen Ihr diagnostischer

Z $\theta$ itschrift fur $\mathrm{Au}^{7} / 8 \theta$ nhei ${ }^{1} / 8$ unde. Bd. 62. Heft 5/6. 18

270

Ansprache.

Scharfblick, Ihre geschickte Hand und Ihre nie erlahmende Sorg-falt Heilung, und denen Ihr warm empfindendes Herz Tröstung brachte.

Als Lehrer haben Sie in Ihren Vorlesungen die Studenten gefesselt, in den Ärztekursen Hörer aus aller Herren Lander an-gezogen und in Ihrer ,Einführung in die Augenheilkunde” ein Lehrbuch geschaffen, das fast nur auf eigener Beobachtung beruht.

Als Forscher haben Sie sich, einer der fruchtbarsten Autoren, auf fast alien Gebieten unseres Faches erfolgreich und zum Teil bahnbrechend betätigt und als Schriftleiter des von Ihnen gegründeten , Zentralblattes für praktische Augenheilkunde"' die Errungenschaften unsérer Wissenschaft zum Allgemeingut des ärztlichen Standes zu machen getrachtet. Ihre Veröffentlichun-gen zeugen von genauester Beobachtung, tiefster Gründlichkeit und unbestechlicher Sachlichkeit, die auf keine herrschende Richtung Rücksicht nimmt, sondern nur das selbst fur richtig befundene gibt. Bemerkenswert erscheint es gerade jetzt, wo durch die Hornhautmikroskopie die Beobachtung des vorderen Augenabschnittes ein erhöhtes Interesse 
gewonnen hat, daß Sie mit viel mangelhafteren Untersuchungsmitteln als Erster die tiefen Hornhautgefäße bei der Keratitis parenchymatosa ent-deckt haben. Grundlegend sind Ihre Beobachtungen über die Veränderungen des Auges bei angeborener und bei erworbener Syphilis und stets mit Ihrem Namen verknüpft bleiben wird das Verfahren der Magnetoperation in der Augenheilkunde.

Solche Erfolge als Arzt, als Lehrer und als Forscher, die das Leben eines Mannes zu einem gesegneten und inhaltsreichen machen, haben das Ihre nicht ausgefüllt: Ihr Geist und Ihr Streben hat sich weitere Grenzen gesteckt. Von brennendem Interesse beseelt, nicht für eine Wissenschaft, sondern für die Wissenschaft, haben Sie die schon während der Schulzeit mit eisernem Fleiße weit über den Rahmen des Schulprogrammes hinaus getriebenen Studien in Sprachen, in Geschichte und in Mathematik bei auf-opferndster Berufsarbeit im Mannesalter fortgesetzt und, man darf sagen, auf alle eines erhabenen Geistes würdigen Gebiete ausgedehnt. Auf wohl vorbereiteten Reisen, die Sie in vier Welt-teile führten, haben Sie Land und Leute erforseht und sich, unterstützt durch ein staunenerregendes Gedächtnis, Kenntnisse erworben, die Sie weit über das Niveau eines Fachgelehrten hinausheben. Ihre Vielseitigkeit und Ihr Gedankenreichtum in Verb.ndung mit einer künstlerischen Beherrschung des Wortes Ansprache. 271 sichern Ihnen die Aufmerksamkeit Ihrer Hörer, zu welcher Frage immer Sie das Wort ergreifen, und haben Sie im Auslande zum würdigen Vertreter deutscher Wissenschaft gemacht.

Mit solchem Rüstzeug sind Sie an Ihr eigentliches Lebens-werk, die Bearbeitung der Geschichte der Augenheilkunde, heran-getreten. Seiner Beendigung haben Sie den größten Teil des letzten Jahrzehntes gewidmet und uns in den neun stattlichen Bänden, die nunmehr als abgeschlossenes Ganzes vor uns liegen, ein Werk beschert, wie es in der Weltliteratur kaum seinesgleichen íindet. Um es auszuführen, dazu gehörte die Sachkenntnis und Erfahrung des Fachgelehrten, der aus jeder Andeutung das rich-rige Krankheitsbild formt, die Sprachkenntnis des Philologen, der die Texte in der Ursprache lesen und deuten kann und die Unparteilichkeit des Geschichtsforschers, der die Zusammenhänge der Geschehnisse richtig erkennt und kritisch beurteilt.

Durch Ihr Vorgehen unmittelbar aus den Quellen zu schöpfen, Quellen, die Sie zum Teil erst selbst aufdeckten, haben Sie eine Fülle neuer und wichtiger Tatsachen gefunden und eine Reihe von Irrtürnern ausgemerzt, die aus manchmal geradezu grotesken Übersetzungs- oder selbst Schreibfehlern entstanden, von Ihren Vorgängern kritiklos übernommen, und durch die Jahrhunderte hindurch geschleppt worden sind.

Die Geschichte einer Wissenschaft ist, so zitieren Sie Goethe, die Wissenschaft selbst. Ihre Geschichte der Augenheilkunde ist mehr: Überall konstruieren Sie den Zusammenhang mit dem geistigen, religiösen und künstlerischen Strömungen der einzelnen Epochen, Sie machen sie zu einer Kulturgeschichte. Und das alles in so klarem Aufbau und so gepflegtem Stile, daß die Lektüre jedem Bildungsbeflissenen zum Genusse wird.

$18^{*}$ Wir aber sind darauf stolz daß ein Augenarzt das geleistet hat. Wir danken Ihnen für das was Sie uns gegeben haben und was Sie uns täglich noch geben und 